LOPES, M.C.; FREIER, M.; MATTE, J.C.; GÄRTNER, M.; FRANZENER, G.; NOGAROLLI, E.L.; SEVIGNANI, A. Acúmulo de nutrientes por cultivares de alface em cultivo hidropônico no inverno. Horticultura Brasileira, Brasília, v. 21, n. 2, p. 211-215, abril/junho 2003.

\title{
Acúmulo de nutrientes por cultivares de alface em cultivo hidropônico no inverno
}

\author{
Mário César Lopes; Matias Freier; Jalmir Dirceu Matte ${ }^{1}$; Marcio Gärtner ${ }^{1}$; Gilmar Franzener ${ }^{1}$; Evandro \\ L. Nogarolli Casimiro' ${ }^{1}$ Alexandro Sevignani ${ }^{1}$; \\ UNIOESTE, R. Pernambuco 1.777, 85960-000 Marechal Cândido Rondon-PR; ${ }^{1}$ Estudante da UNIOESTE; E.mail: mclopes@unioeste.br
}

\begin{abstract}
RESUMO
Avaliou-se o desempenho de seis cultivares de alface do grupo americana, em sistema hidropônico "NFT". O experimento foi conduzido na UNIOESTE, de junho a agosto de 2001 em delineamento de blocos ao acaso, com quatro repetições e seis tratamentos, constituídos pelos cultivares Lorca, Tainá, Havem, Empire 2000, Lucy Brown e Kaesar. Avaliaram-se a produção de matéria fresca e seca da parte aérea, concentração e absorção de macro e micronutrientes. As cultivares Lorca e Havem obtiveram maior produção de matéria fresca, não diferindo estatisticamente entre si, estas apenas apresentaram concentração menor dos nutrientes $\mathrm{Ca}$ e $\mathrm{Cu}$ em relação às demais cultivares. Em termos de concentração de nutrientes na parte aérea, não houve diferença estatística entre as cultivares para os nutrientes $\mathrm{N}, \mathrm{P}, \mathrm{K}$ e $\mathrm{Mn}$. Nos nutrientes $\mathrm{Ca}, \mathrm{Mg}, \mathrm{Cu}$ e $\mathrm{Zn}$, ocorreu grande variação na concentração. No acúmulo de nutrientes $\left(\mathrm{kg} \cdot \mathrm{ha}^{-1}\right)$, não observou-se diferença estatística entre as cultivares para $\mathrm{N}$ e $\mathrm{P}$, enquanto para os outros nutrientes avaliados, as cultivares Lorca, Havem e Empire 2000 foram superiores, sendo também as que apresentaram maior produção de matéria fresca e seca.
\end{abstract}

Palavras-chave: Lactuca sativa L., produção, hidroponia, nutrição mineral.

\begin{abstract}
Nutrient accumulation by lettuce cultivars under hydroponic culture in the winter

The performance of six lettuce cultivars of the American group, under hydroponic system "NFT" was evaluated in Marechal Cândido Rondon, Paraná State, Brazil. The experiment was performed from June to August 2001, in randomized blocks designed, with four replication and six treatments, constituted by cultivars Lorca, Tainá, Havem, Empire 2000, Lucy Brown and Kaesar. Yield of fresh mass and dry matter of the shoot, concentration and accumulation of macro and micronutrients were evaluated. 'Lorca' and 'Havem' presented larger production of fresh matter. These cultivars presented smaller concentration of $\mathrm{Ca}$ and $\mathrm{Cu}$ in relation to the others cultivars. The concentration of nutrients in the shoot was not different among cultivars for $\mathrm{N}, \mathrm{P}, \mathrm{K}$ and $\mathrm{Mn}$. For $\mathrm{Ca}, \mathrm{Mg}, \mathrm{Cu}$ and $\mathrm{Zn}$, bigger variation in the concentration was observed. No statistical difference was observed among cultivars for the extraction of $\mathrm{N}$ and $\mathrm{P}$, while for the other evaluated nutrients, the cultivars Lorca, Havem and Empire 2000 were superior, being also the ones which produced more fresh and dry matter.
\end{abstract}

Keywords: Lactuca sativa L., yield, soilless-culture, mineral nutrition.

(Recebido para publicação em 23 de maio de 2002 e aceito em 25 de março de 2003)

\begin{abstract}
A alface é a hortaliça folhosa mais comercializada no Brasil, sendo boa fonte de vitaminas e sais minerais, destacando-se seu elevado teor de vitamina A. É adaptada a clima ameno, sendo própria para cultivo no inverno quando atinge as maiores produções.

Em cultivo hidropônico sob ambiente protegido, a alface não está exposta a fatores adversos do meio ambiente, fica protegida de geadas, chuvas intensas, granizo e ventos fortes, com ganho na produtividade e qualidade, fatores que contribuem para o fornecimento constante aos pontos de venda, trazendo satisfação ao consumidor. Por ser uma técnica relativamente nova no Brasil, não foi ainda adequadamente explorada em termos de pesquisa e portanto são pouquíssimos relatos sobre as cultivares testadas.
\end{abstract}

Sendo produto perecível e consumido in natura, a preocupação com a qua- lidade da alface, seja nutricional, ou sanitária, deve ser mantida em todos os seguimentos envolvidos na produção e comercialização (Resende, 1991). Neste contexto, os cultivos hidropônicos representam uma alternativa à cultura convencional, por possibilitarem a obtenção de produtos de qualidade superior, mais uniformes, com maior produtividade, menor custo de mão-de-obra, menor gasto de água e de insumos agrícolas e preservação do meio ambiente. No Brasil, os cultivos hidropônicos são recentes, mas já podem ser encontrados nos cinturões verdes de algumas capitais, e também em algumas cidades do interior. A alface é a espécie mais difundida entre os produtores hidropônicos, provavelmente devido ao seu pioneirismo como cultura hidropônica no país, bem como, por se tratar de cultura de manejo mais fácil e principalmente por ser de ciclo curto
(45-60 dias) garantindo assim retorno de capital mais rápido. A maior fração dos cultivos hidropônicos de alface, no país, é feita pela técnica do fluxo laminar de nutrientes (NFT = Nutrient Film Tecnique).

Os primeiros produtores brasileiros instalaram essa técnica a partir de informações geradas por pesquisas executadas na Europa, Estados Unidos e Austrália, onde as condições de clima, custos de produção e mercado diferem muito das locais. Isso proporcionou muitas vezes resultados diferentes dos esperados. Frente a essa situação, alguns produtores desistiram do cultivo, outros criaram e adaptaram suas próprias tecnologias, baseando-se em tentativas e na troca de experiência (Koefender, 1996).

A cultivar Lucy Brown no sistema de hidroponia apresentou menores valores de matéria fresca de folhas (276,11 g) em relação às cultivares Kaesar $(356,11$ g) e Tainá (356 g) (Pedrosa et 
al., 1999). Garcia et al. (2000) estudando as cultivares de alface Lucy Brown e Tainá em cultivo hidropônico no verão, não obtiveram diferença estatística significativa em termos de acúmulo de nutrientes por planta. Sediyama et al. (2000) conduzindo experimento com as mesmas cultivares não verificaram diferença de produção entre Lorca (292,78 g), Lucy Brown (303,33 g) e Tainá (297,78 g). Furlani (1997) encontrou para alface crespa as concentrações de $39,1,6,8,65,3,11,8$ e 3,3 g. $\mathrm{kg}^{-1}$ respectivamente de $\mathrm{N}, \mathrm{P}, \mathrm{K}, \mathrm{Ca}$ e $\mathrm{Mg}$ e para $\mathrm{Cu}, \mathrm{Mn}$ e $\mathrm{Zn}, 2,3$ de $\mathrm{Cu}, 133,2$ de $\mathrm{Mn}$ e 24,3 mg.kg ${ }^{-1}$ de Zn.

Silva (1999) apresenta como valores de referência de concentração de macronutrientes em tecido foliar de alface 30-50, 4-7, 50-80, 15-25, 4-6 g.kg-1 de N, P, K, Ca e Mg e de micronutrientes 7-20, 30-150 e 30-100 mg. $\mathrm{kg}^{-1}$ de $\mathrm{Cu}$, $\mathrm{Mn}$ e $\mathrm{Zn}$ respectivamente, semelhantes aos valores indicados por Raij et al., (1996).

Em cultivos hidropônicos, a absorção de nutrientes é muito influenciada pela espécie vegetal, cultivares e ambiente, sendo proporcional à concentração de nutrientes na solução próxima às raízes (Adams, 1994; Furlani et al., 1999). O conhecimento das exigências nutricionais de diferentes cultivares de alface produzidas em hidroponia é de fundamental importância para se formular uma solução balanceada.

Atualmente no Brasil, já existem informações de pesquisa a respeito de alface em 'NFT', as quais foram desenvolvidas em estações experimentais, centros de pesquisas e universidades. No entanto, essas informações ainda não são suficientes e, é necessário que mais pesquisas sejam realizadas para compreender melhor essa técnica, nas condições locais e para essa cultura, para assim, poder resolver os problemas que os produtores possam vir a ter, permitindo o avanço dessa área de produção agrícola e do conhecimento científico (Koefender, 1996; Bernardes, 1997; Cohen, 1998).

Este estudo teve o objetivo de avaliar o desempenho de seis cultivares de alface americana, em cultivo hidropônico "NFT"(Nutrient Film Technique), no período de inverno, quanto à concentra- ção e acúmulo de macro e micronutrientes nas plantas, e sua influência na produção, haja vista que há escassez dessas informações para as nossas condições.

\section{MATERIAL E MÉTODOS}

O presente trabalho foi conduzido na UNIOESTE, campus de Marechal Cândido Rondon (PR). O experimento consistiu de duas bancadas de $1,5 \mathrm{~m}$ de largura x $12 \mathrm{~m}$ de comprimento e $2 \%$ de declividade. Foram empregados tubos de PVC (75 mm) em formato de canoa perfurados, com diâmetro de $5,0 \mathrm{~cm} \mathrm{e}$ espaçados em $30 \mathrm{~cm}$. A estufa utilizada foi do tipo túnel alto, com 4,0 m de pé direito, cobertura plástica de 150 micras de espessura e laterais protegidas com telas de polipropileno preto com $50 \%$ de sombreamento.

O delineamento experimental adotado foi de blocos inteiramente casualizados, com quatro repetições e seis tratamentos, constituídos por seis cultivares de alface do grupo americana (Lorca, Tainá, Havem, Empire 2000, Lucy Brown e Kaesar). A semeadura foi realizada em placas de espuma fenólica nas dimensões de $2 \mathrm{~cm} \mathrm{x} 2 \mathrm{~cm}$ x $2 \mathrm{~cm}$, com capacidade para 345 plantas em 12/ 06/01 e o transplante para a fase de crescimento em 11/07 e para a fase de produção em 23/07. A colheita foi realizada em 24/08/01, totalizando 73 dias até o ponto de colheita. A espuma fenólica é um substrato estéril, de fácil manuseio e que oferece ótima sustentação para as plântulas, reduzindo sensivelmente os danos durante a operação de transplante (Furlani et al., 1999).

Foi utilizado o sistema hidropônico fechado com recirculação da solução a cada 10 minutos durante 24 horas, controlado automaticamente por timer, sendo que no sistema de retorno da solução foi adaptado um injetor de oxigênio composto por duas conexões rosqueáveis com perfuração lateral para a entrada de ar, o qual era injetado diretamente na solução nutritiva.

$\mathrm{O}$ pH da solução variou de 5,5 a 6,5, sendo a mesma renovada a cada 15-20 dias não havendo necessidade de ajustes. A água utilizada era de poço semiartesiano, com pH de 6,7 e condutividade elétrica de $0,2 \mathrm{mS} . \mathrm{cm}^{-1}$.

Para a nutrição das plantas, utilizouse uma solução nutritiva comercial, nas proporções descritas na Tabela 1.

As soluções comerciais utilizadas são constituídas pelos seguintes nutrientes: kristalon amarelo (13-40-13) 4,4\% $\mathrm{NO}_{3}-\mathrm{N}+8,6 \% \mathrm{NH}_{4}-\mathrm{N}, 40 \%$ de $\mathrm{P}_{2} \mathrm{O}_{5} \mathrm{e}$ $13 \%$ de $\mathrm{K}_{2} \mathrm{O}$; kristalon branco (15-5-30) $11,3 \% \mathrm{NO}_{3}-\mathrm{N}+3,7 \% \mathrm{NH}_{4}-\mathrm{N}, 5 \%$ de $\mathrm{P}_{2} \mathrm{O}_{5}, 30 \%$ de $\mathrm{K}_{2} \mathrm{O}, 3 \%$ de $\mathrm{MgO}$ e $2 \%$ de $\mathrm{S}$ e kristalon laranja (6-12-36) 4,5\% $\mathrm{NO}_{3}-\mathrm{N}+1,5 \% \mathrm{NH}_{4}-\mathrm{N}, 12 \%$ de $\mathrm{P}_{2} \mathrm{O}_{5}$, $36 \%$ de $\mathrm{K}_{2} \mathrm{O}, 3 \%$ de $\mathrm{MgO}$ e $8 \%$ de $\mathrm{S}$, adicionados ainda às fórmulas os micronutrientes B 0,025\%, Mo 0,004\%, Cu EDTA 0,01\%, Fe EDTA 0,07\%, Mn EDTA $0,04 \%$ e Zn EDTA 0,025\%. O Nitrato de Cálcio especial apresenta $14,5 \%$ de $\mathrm{N}$ nítrico, $1 \%$ de $\mathrm{N}$ amoniacal e $19 \%$ de cálcio hidrossolúvel, sendo ainda utilizado a complementação com Tenso Cocktail que é composto por B $0,25 \%$, Ca EDTA $2,57 \%$, Cu EDTA $0,53 \%$, Fe EDTA $2,10 \%$, Fe DTPA $1,74 \%$, Mn EDTA $2,57 \%$, Mo 0,13\% e Zn EDTA 0,53\%.

Após a semeadura aplicou-se apenas água para manter a espuma úmida, num período de três dias. Em seguida utilizou-se a solução para estabelecimento e enraizamento (Tabela 1). Esta solução foi utilizada durante a permanência das plantas nas bandejas até as mesmas atingirem quatro folhas definitivas e estarem prontas para o transplante na bancada de crescimento (vazão da solução 1 L.min ${ }^{-1}$ ), permanecendo na mesma até atingirem de seis a oito folhas e serem transplantadas para a bancada definitiva (vazão de 1,5 a 2,0 L.min ${ }^{-1}$ ), ficando nesta até a colheita. Tanto na bancada de crescimento como na bancada definitiva foi utilizada a mesma solução.

Sempre que necessário completava-se a água do reservatório, havendo assim a necessidade de correção da solução, a qual era feita através da condutividade elétrica, procurando mantê-la entre $2,0 \mathrm{mS} . \mathrm{cm}^{-1}$ e 2,2 mS.cm-1 adicionando-se as soluções de reposição A e B (Tabela 1). Para aumentar cada $0,1 \mathrm{mS} . \mathrm{cm}^{-1}$, foram adicionados $250 \mathrm{~mL}$ da solução A e $250 \mathrm{ml}$ da solução B. Também adicionou-se $20 \mathrm{~g}$ por semana de Tenso Cocktail para cada 1000 L da solução. 
Tabela 1. Soluções nutritivas utilizadas no estabelecimento inicial, crescimento das mudas e na produção final até a colheita e reposições empregadas no experimento. Marechal Cândido Rondon, UNIOESTE, 2001.

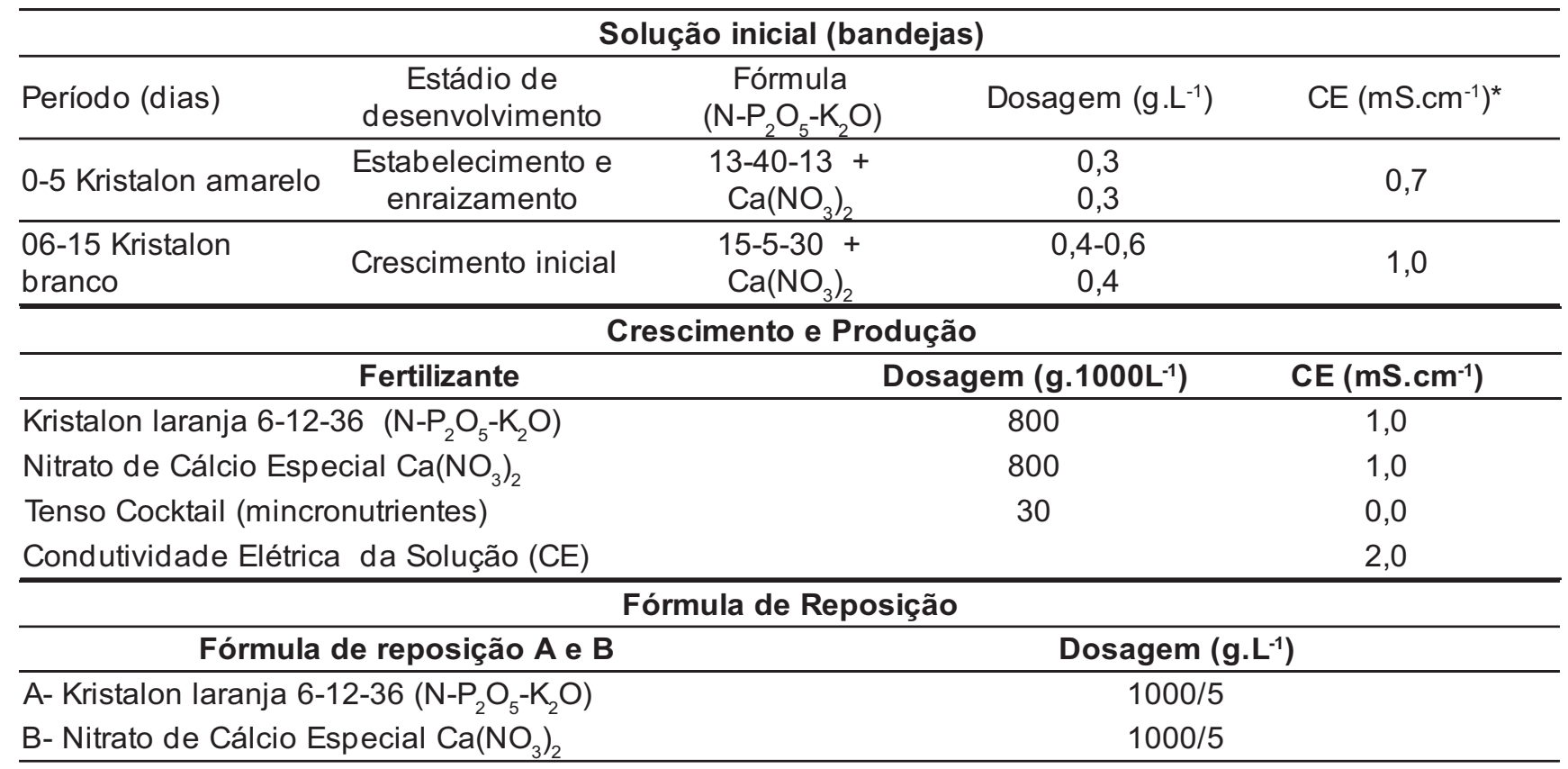

A matéria fresca (g.planta $\left.{ }^{-1}\right)$ foi determinada pesando-se a parte aérea de cada planta da repetição, utilizando-se balança digital.

As plantas foram secas em estufa de circulação forçada de ar a temperatura de $65^{\circ} \mathrm{C}$ até atingirem peso constante para a determinação da matéria seca com a utilização de uma balança analítica. Após determinada a matéria seca das plantas, as mesmas foram moídas em moinho tipo Willey, peneira de 40 mesh. Para a retirada da amostra, foram coletadas folhas na metade a dois terços do ciclo recém desenvolvidas conforme recomendação de Silva (1999) e Raij et al., (1996), obtendo-se uma amostra de $1 \mathrm{~g}$ para a análise de N, P, K, $\mathrm{Ca}, \mathrm{Mg}$ e $\mathrm{Zn}, \mathrm{Cu}, \mathrm{Mn}$, de acordo com a metodologia descrita por Miyazawa et al. (1992). Os dados obtidos foram submetidos à análise de variância, sendo as médias comparadas entre si pelo teste de Tukey a $5 \%$ de probabilidade.

\section{RESULTADOS E DISCUSSÃO}

As cultivares Lorca e Havem, que mais produziram em termos de matéria fresca (Tabela 3), não diferiram estatisticamente entre si em todos os nutrientes avaliados, tanto no acúmulo quanto na concentração. Estas apenas tiveram concentração menor dos nutrientes $\mathrm{Ca}$ e $\mathrm{Cu}$ em relação às demais cultivares (Tabela 2).

Em termos de concentração de nutrientes na parte aérea, não houve diferença estatística entre as cultivares para os nutrientes N, P, K e Mn (Tabela 2). Para os nutrientes $\mathrm{Ca}, \mathrm{Mg}, \mathrm{Cu}$ e $\mathrm{Zn}$, houve variação na concentração, não havendo correlação com a produção de matéria fresca.

De maneira geral as concentrações de N, K e Ca estão de acordo com os valores de referência citados por Silva (1999) e Raij et al., (1996), sendo que o $\mathrm{P}$ se encontra abaixo, o que pode ser explicado pela coleta de folhas com pleno desenvolvimento e o elemento ter sido translocado via floema para regiões mais jovens ainda em fase de crescimento. No caso do Mg as concentrações estão um pouco abaixo dos valores de referência, provavelmente pelas concentrações adequadas de $\mathrm{Ke} \mathrm{Ca}$ o que pode ter inibido competitivamente com sua absorção, mas não chegando a apresentar sintomas de carência.

No caso dos micronutrientes analisados, o $\mathrm{Cu}$ se encontra dentro dos valores de referência citados por Silva (1999) e Raij et al., (1996) e o Zn apresentando valores mais baixos. As altas concentrações de $\mathrm{Mn}$ diminuem a absorção de Zn e Fe principalmente (Marschner, 1995). De acordo com Jones Junior et al., (1991) concentrações de Mn acima de 250 mg. $\mathrm{kg}^{-1}$ são consideradas altas. Segundo Marschner (1995) a toxidez por Mn causa necroses e manchas nas folhas. Apesar dos valores obtidos estarem bem elevados, não foram observados sintomas de toxidez, mas provavelmente foi o fator responsável pelas concentrações de $\mathrm{Zn}$ obtidas.

No acúmulo de nutrientes $\left(\mathrm{kg} \cdot \mathrm{ha}^{-1}\right)$, não foram observadas diferenças estatísticas entre as cultivares para $\mathrm{N}$ e $\mathrm{P}$, onde para os outros nutrientes avaliados, as cultivares Lorca, Havem e Empire 2000, exceto a cultivar Empire 2000 para $\mathrm{Mg}$, foram superiores, sendo também as que apresentaram maior produção de matéria fresca e seca na parte aérea (Tabela 3), não diferindo entre si.

Obteve-se variação significativa nos nutrientes $\mathrm{Ca}, \mathrm{Mg}$, $\mathrm{Cu}$ e $\mathrm{Zn}$ para as seis cultivares em estudo, o mesmo não acontecendo para N, P, K e Mn. Esses resultados diferem dos obtidos por Garcia et al. (2000) onde não houve diferenças nas concentrações de nutrientes para as cultivares Lorca, Tainá e Lucy Brown. 
Tabela 2. Acúmulo e concentração de macro e micronutrientes em plantas de alface em cultivo hidropônico no inverno. Marechal Cândido Rondon, UNIOESTE, 2001.

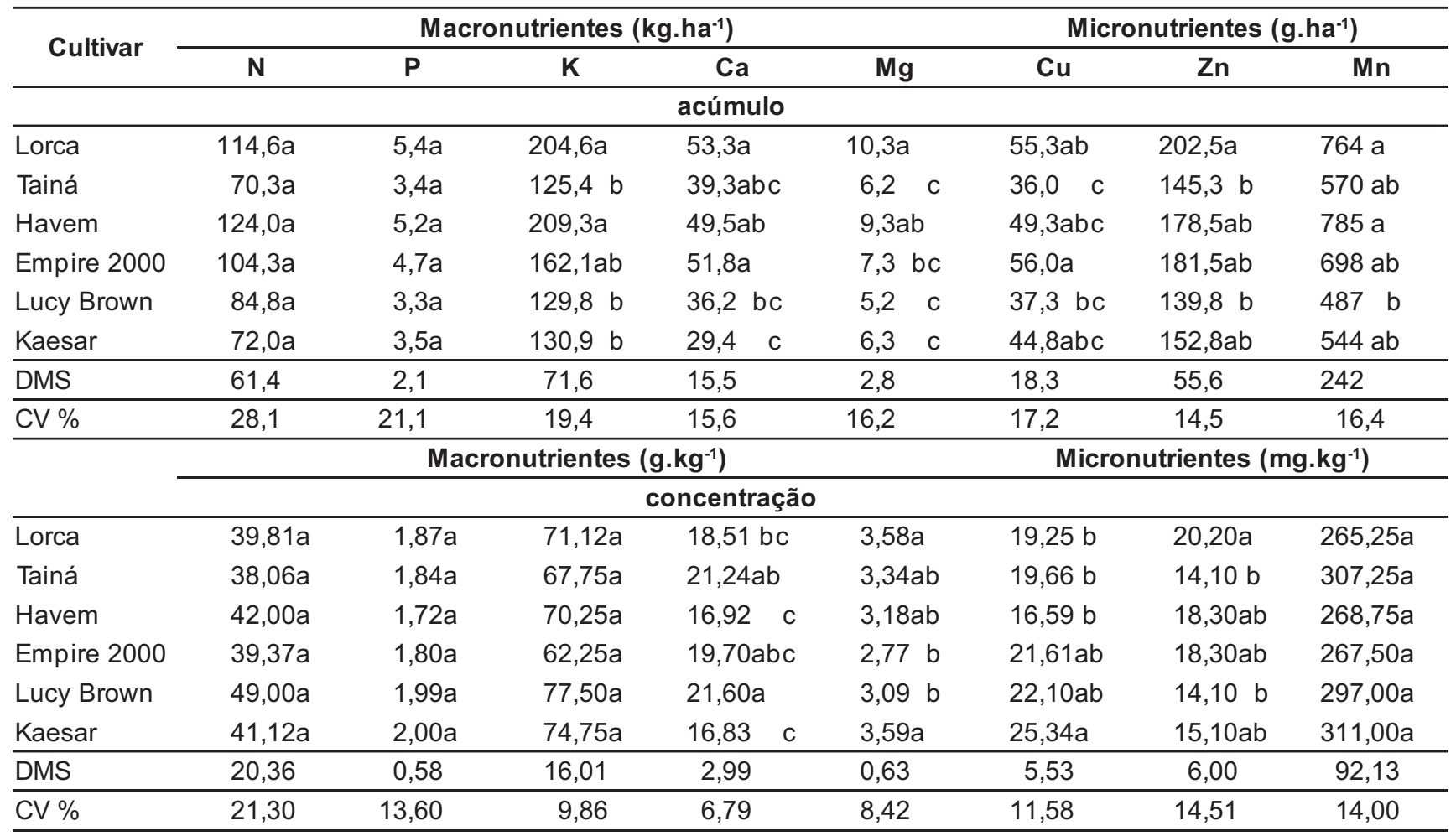

Médias seguidas de mesma letra nas colunas não diferem entre si pelo teste de Tukey $(\mathrm{P}<0,05)$.

Tabela 3. Produção de matéria fresca e seca na parte aérea em plantas de alface em cultivo hidropônico no inverno. Marechal Cândido Rondon, UNIOESTE, 2001.

\begin{tabular}{|c|c|c|}
\hline \multirow{2}{*}{ Cultivar } & Matéria fresca & Matéria seca \\
\hline & g. planta $^{-1}$ & g.planta-1 \\
\hline Lorca & $647,3 a$ & $24,0 a$ \\
\hline Tainá & $464,5 \mathrm{~b}$ & $15,4 \mathrm{~b}$ \\
\hline Havem & $577,2 a b$ & $24,8 a$ \\
\hline Empire 2000 & $539,0 a b$ & $21,9 a b$ \\
\hline Lucy Brown & $450,7 b$ & $14,0 \mathrm{~b}$ \\
\hline Kaesar & $442,7 b$ & $14,5 b$ \\
\hline$\overline{D M S}$ & 171,52 & 8,11 \\
\hline CV \% & 14,33 & 18,46 \\
\hline
\end{tabular}

Médias seguidas de mesma letra nas colunas não diferem entre si pelo teste de Tukey $(\mathrm{P}>0,05)$.

As concentrações de alguns nutrientes $(\mathrm{P}, \mathrm{Ca}, \mathrm{Zn}, \mathrm{Cu}, \mathrm{Mn})$ por planta, diferem dos apresentados por Furlani (1999), o que pode ser explicado pelos dados terem sido obtidos a partir de alface crespa comum.

As soluções comerciais utilizadas, promoveram uma nutrição adequada com boa produtividade em todas as cultivares avaliadas.
Conclui-se que, em cultivo hidropônico, sistema NFT, todas as cultivares avaliadas apresentaram boa produtividade, sendo que Lorca, Havem e Empire 2000 foram as que mais se destacaram quanto a qualidade, maior acúmulo de nutrientes, bem como maior produção de matéria fresca e seca, onde maior massa de matéria fresca deverá possibilitar melhor rendimento para res- taurantes que comercializam alface no sistema de "quilo".

\section{LITERATURA CITADA}

ADAMS, P. Nutrition of greenhouse vegetables in NFT an hydroponic systems. Acta Horticulturae, n. 361, p. 254-257, 1994.

BERNARDES, L.J.L. Hidroponia da alface: uma história de sucesso. Piracicaba: Estação Experimental de Hidroponia “Alface \& Cia”, 1997. 129 p. 
COHEN, A.I. Análise do comportamento da alface em sistema hidropônico tipo NFT, com e sem o uso de nutrientes quelatizados na solução nutritiva. Jaboticabal: FCAV - UNESP, 1998, 91 p. (Tese mestrado)

FURLANI, P.R. Instruções para o cultivo de hortaliças de folhas pela técnica de hidroponia - NFT. Campinas: Instituto Agronômico, 1997. 30 p. FURLANI, P.R.; BOLONHEZI, D.; SILVEIRA L.C.P.; FAQUIN, V. Nutrição mineral de hortaliças, preparo e manejo de soluções nutritivas. Informe Agropecuário, Belo Horizonte, v. 20, n. 20001,1999

FURLANI, P.R.; SILVEIRA, L.C.P BOLONHEZI, D.; FAQUIN, V. Cultivo hidropônico de plantas. Campinas: Instituto Agronômico , 1999. 52 p.

GARCIA, N.C.P; PEDROSA, M.W.; SEDIYAMA M.A.N.; LIMA P.C. Absorção de nutrientes por diferentes cultivares de alface em cultivo hidropônico no período de verão. Horticultura Brasileira, Brasília, v. 18, p. 246-247, 2000.
JONES JUNIOR, J.B.; WOLF, B.; MILLS, H.A.

Plant analysis handbook, a pratical sampling, preparation, analysis, and interpretation guide. Georgia, USA: Micro-macro, 1991 p. 35-38.

KOEFENDER, V.N. Crescimento e absorção de nutrientes pela alface cultivada em fluxo laminar de solução. Piracicaba: ESALQ, 1996, 85 p. (Tese mestrado).

MARSCHNER, H. Mineral nutrition of higher plants. 2. ed. New York: Academic Press, 1995. 889 p.

MIYAZAWA, M.; PAVAN, M.A.; BLOCH M.F.M.; Análise Química de Tecido Vegetal. IAPAR, Circular 74, 1992. 17 p.

PEDROSA, M.W.; SEDIYAMA, M.A.N.; GARCIA, N.C.P; SALGADO, L.T.; Produção de alface hidropônico em condições de inverno. Horticultura Brasileira, Brasília, v. 18, p. 242-243, 2000
RAIJ, B.; CANTARELLA, H.; QUAGGIO, J.A. FURLANI, A.M.C. Recomendações de adubação e calagem para o Estado de São Paulo, 2.ed. Campinas, Instituto Agronômico \& Fundação IAC, 1996. $285 \mathrm{p}$.

RESENDE, A.C. Controle da qualidade de hortaliças comercializadas nas centrais de abastecimento. In. Seminário internacional sobre qualidade de hortaliças e frutas frescas. Anais Brasília EMBRAPA- CNPH, 1991.

SEDIYAMA, M.A.N.; PEDROSA, M.W.; GARCIA, N.C.P; GARCIA, S.R.L. Seleção de cultivares de alface para cultivo hidropônico. Horticultura Brasileira, Brasília, v. 18, p. 244-245, 2000.

SILVA, F.C. Manual de análises químicas de solos, plantas e fertilizantes. Embrapa Solos, Embrapa Informática Agropecuária; organizador Fábio César da Silva. Brasília: Embrapa Comunicação para Transferência de Tecnologia, 1999. 370 p. 